\title{
Oncotropic H-1 parvovirus infection degrades HIF-1 $\alpha$ protein in human pancreatic cancer cells independently of VHL and RACK1
}

\author{
IL-RAE CHO $^{1}$, SIRICHAT KAOWINN ${ }^{1}$, JEONG MOON ${ }^{1}$, JIWON SOH ${ }^{2}$, HO YOUNG KANG ${ }^{2}$, CHO-ROK JUNG $^{3}$, \\ SANGTAEK OH ${ }^{4}$, HAYNE SONG ${ }^{5}$, SANG SEOK KOH ${ }^{5}$ and YOUNG-HWA CHUNG ${ }^{1}$ \\ ${ }^{1}$ BK21+, Department of Cogno-Mechatronics Engineering and ${ }^{2}$ Department of Microbiology, Pusan National University, \\ Busan 609-736; ${ }^{3}$ Gene Therapy Research Center, Korea Research Institute of Bioscience and Biotechnology, \\ Daejeon 305-333; ${ }^{4}$ Department of Bio and Fermentation Convergence Technology, Kookmin University, \\ Seoul 136-702; ${ }^{5}$ Department of Biological Sciences, Dong-A University, Busan 604-714, Republic of Korea
}

Received October 19, 2014; Accepted December 5, 2014

DOI: $10.3892 /$ ijo.2015.2922

\begin{abstract}
Overexpression of HIF-1 $\alpha$, a transcription factor responsive to hypoxia, is frequently observed in malignant tumors, which sometimes show resistance to chemotherapy and radiation therapy. Consequently, decrease of HIF-1 $\alpha$ through virotherapy offers a logical strategy for the treatment of aggressive tumors. In this study, we found that infection with the oncolytic $\mathrm{H}-1$ parvovirus decreased HIF-1 $\alpha$ protein levels in pancreatic cancer cells under $\mathrm{CoCl}_{2}$ or hypoxia. The H-1 virus-induced decrease of HIF-1 $\alpha$ was regulated by a proteasome-mediated pathway. Suppression of VHL, an E3 ligase and a critical regulator of HIF-1 $\alpha$, or enforced expression of UCP, an E2 ubiquitin-conjugating enzyme, failed to inhibit the $\mathrm{H}-1$ virus-induced decrease of HIF-1 $\alpha$. Furthermore, siRNAmediated suppression of RACK1, another regulator of HIF-1 $\alpha$, did not prevent $\mathrm{H}-1$ viral infection from lowering HIF-1 $\alpha$ protein levels. Although decrease of HIF-1 $\alpha$ was observed after $\mathrm{H}-1$ viral infection, constitutive expression of HIF- $1 \alpha$ limited H-1 viral replication. After combined treatment with H-1 parvovirus and YC-1, an inhibitor of HIF-1 $\alpha$, the apoptosis of pancreatic cancer cells was greater than after treatment with $\mathrm{H}-1$ virus alone or YC-1 alone. Accordingly, we propose that $\mathrm{H}-1$ parvovirus could be used with $\mathrm{YC}-1$ as a potential therapeutic agent against aggressive tumors exhibiting hypoxia and increased levels of HIF-1 $\alpha$.
\end{abstract}

\section{Introduction}

Hypoxia is a prevalent feature of solid tumors. Normal tissues have an oxygen partial pressure of $50-60 \mathrm{mmHg}$, compared with $10 \mathrm{mmHg}$ or less in most solid tumors $(1,2)$. The hypoxic environment induces adaptive changes in tumor cell metabo-

Correspondence to: Professor Young-Hwa Chung, BK21+, Department of Cogno-Mechatronics Engineering, Pusan National University, Busan 609-735, Republic of Korea

E-mail: younghc@pusan.ac.kr

Key words: HIF-1 $\alpha$, H-1 virus, VHL, RACK1, virotherapy lism, which can distort the local microenvironment. These changes are clinically important because hypoxia enhances resistance to chemotherapy and radiation therapy and it is predictive of metastasis and malignancy (1).

Members of the HIF family of transcription factors are crucial regulators of adaptive cellular responses to hypoxia. Overexpression of HIF-1 $\alpha$ is a hallmark of diverse tumors and its constitutive activation is frequently observed in aggressive tumor phenotypes (3). HIF- $1 \alpha$ is degraded via a ubiquitinmediated, proteasome-dependent pathway under normoxic conditions (4). The oxygen-dependent turnover of HIF-1 $\alpha$ is regulated by prolyl HIF hydroxylase (PHD) enzymes that hydroxylate two conserved proline residues located in the oxygen-dependent degradation domain of HIF-1 $\alpha$. During normoxia, hydroxylation of HIF-1 $\alpha$ allows it to bind to the von Hippel-Lindau (VHL) protein, a recognition component of the E3 ubiquitin ligase complex. The interaction promotes the ubiquitination of HIF-1 $\alpha$, which is mediated by a complex that includes VHL, Elongin-B, Elongin-C, Cullin-2 and Rbx1, and leads to the degradation of HIF-1 $\alpha(5,6)$.

Pancreatic cancer has an extremely poor prognosis, with a 5 -year survival rate of $<5 \%(7,8)$. The only potential curative treatment for pancreatic cancer is surgery, but only $10-20 \%$ of patients are candidates for surgery at the time of presentation. Because most patients are diagnosed with malignant pancreatic cancers of advanced metastatic stages, the therapeutic options are very limited (9). Moreover, the efficacy of current treatments, such as monoclonal antibodies $(10,11)$ or small molecule tyrosine kinase inhibitors (12), is low. The use of viral vectors derived from adenovirus, vaccinia virus, herpesvirus, or $\mathrm{H}-1$ parvovirus has been suggested as a promising way to expand the current options for pancreatic cancer therapy (13-15).

The autonomous $\mathrm{H}-1$ parvovirus comprises a small, nonenveloped icosahedral particle with a single-stranded DNA genome of $\sim 5 \mathrm{~kb}$ (16). $\mathrm{H}-1$ parvovirus has received attention because of its oncotropic and oncotoxic properties (17). Its lytic cycle leads to tumor cell death via an apoptotic or a lysosomal pathway (18). It was shown that administration of $\mathrm{H}-1$ virus prolongs the survival of rats with transplanted glioma cells in the brain without having cytotoxic effects on other tissues (19). 
Furthermore, clinical phase I/IIa trials have been performed in patients with progressive primary or recurrent glioblastoma multiforme, the most malignant type of glial tumor (20). In pancreatic tumors, another aggressive cancer model, IFN- $\gamma$ released from immune cells accelerates the efficacy of $\mathrm{H}-1$ virus-mediated oncolysis in pancreatic cancer cells (21). H-1 virus uses cellular SMAD4, a transcription factor that can bind to the viral $\mathrm{P} 4$ promoter, for efficient replication in pancreatic cancer cells (22).

In this study, we investigated whether $\mathrm{H}-1$ parvovirus could downregulate HIF-1 $\alpha$, a malignant tumor marker, to trigger apoptosis in pancreatic cancer cells. We found that $\mathrm{H}-1$ parvovirus reduces HIF-1 $\alpha$ protein levels independently of VHL and RACK1. Furthermore, combined treatment with H-1 parvovirus and $\mathrm{YC}-1$ accelerated the apoptosis of pancreatic cancer cells constitutively expressing HIF-1 $\alpha$, suggesting that $\mathrm{H}-1$ parvovirus could be used with $\mathrm{YC}-1$ as a therapeutic agent against aggressive pancreatic tumors.

\section{Materials and methods}

Cell culture and virus amplification. Normal rat kidney (NRK) cells and MIA PaCa-2 cells were cultured in DMEM supplemented with $10 \%$ FBS and $1 \%$ penicillin and streptomycin. MIA PaCa-2 cells with stable knockdown of VHL (Miapaca-shVHL cells) and the corresponding control cells (Miapaca-shGFP cells) were additionally supplemented with puromycin $(1 \mu \mathrm{g} / \mathrm{ml})$. H-1 parvovirus was purchased from American Type Culture Collection (Manassas, VA, USA) and was propagated in NRK cells. The virus was purified as described elsewhere (23) and the viral titer was determined as $\mathrm{TCID}_{50} / \mathrm{ml}$.

Reagents and antibodies. Cycloheximide and YC-1 were purchased from Sigma (St. Louis, MO, USA) and MG132 was obtained from Calbiochem (San Diego, CA, USA). For immunoblotting, anti- $\beta$-tubulin and HRP-conjugated secondary antibodies were purchased from Santa Cruz Biotechnology (Santa Cruz, CA, USA) and the anti-HIF-1 $\alpha$ antibody was obtained from BD Biosciences (San Jose, CA, USA). The anti-caspase-8 antibody was purchased from Cell Signaling (Danvers, MA, USA). Polyclonal anti-H-1 parvovirus antibodies were prepared after immunization of rabbit 3 times with purified $\mathrm{H}-1$ virus. For construction of stable pancreatic cancer cells in which VHL protein expression was stably suppressed, the pRS-shVHL vector was purchased from OriGene (Rockville, MD, USA).

Western blot assay. Cells were harvested and lysed with lysis buffer (150 mM NaCl, 1\% NP-40, 50 mM Tris-HCl, pH 7.5) containing $0.1 \mathrm{mM} \mathrm{Na}_{2} \mathrm{VO}_{3}, 1 \mathrm{mM} \mathrm{NaF}$ and protease inhibitors (Sigma). For immunoblotting, proteins from whole cell lysates were resolved by 10 or $12 \%$ SDS-PAGE and then transferred to nitrocellulose membranes. Primary antibodies were used at $1: 1,000$ or 1:2,000 dilutions and secondary antibodies conjugated with horseradish peroxidase were used at a dilution of 1:2,000 in 5\% non-fat dry milk. After the final washing steps, nitrocellulose membranes were exposed to enhanced chemiluminescence reagent and imaged using LAS 4000-mini (Fuji, Tokyo, Japan).
RT-PCR analysis. Total RNA was extracted from cells using an RNeasy Protect Cell Mini kit (Qiagen, Valencia, CA, USA) in accordance with the manufacturer's instructions. Three micrograms of total RNA was converted to cDNA using Superscript II Reverse Transcriptase (Invitrogen, Carlsbad, CA, USA) and PCR was performed using specific primers described elsewhere (24). The cDNA in each sample was diluted and PCR was run for the optimized number of cycles. $\beta$-actin mRNA was measured as an internal standard. After amplification, the products were subjected to electrophoresis on $1.5 \%$ agarose and detected with ethidium bromide staining.

Statistical analysis. Data are presented as the mean \pm standard error of the mean (SEM). Student's t-test was used for statistical analysis, with $\mathrm{P}$ values $<0.05$ defined as statistically significant.

\section{Results}

$H-1$ parvovirus infection induces rapid degradation of the HIF-1 $\alpha$. Because many solid tumors display features of hypoxia $(1,2)$, we wondered how tumor cells growing under hypoxic conditions would respond to infection with the oncotropic $\mathrm{H}-1$ virus. To test this, we grew MIA $\mathrm{PaCa}-2$ pancreatic cancer cells under $\mathrm{CoCl}_{2}$ (which mimics hypoxic conditions), infected them with $\mathrm{H}-1$ virus and measured the levels of $\mathrm{HIF}-1 \alpha$ protein at $12 \mathrm{~h}$ post-infection. We found that $\mathrm{H}-1$ virus infection significantly reduced the levels of HIF-1 $\alpha$ protein, which had been increased by $\mathrm{CoCl}_{2}$ (Fig. 1A). Furthermore, when cells under hypoxia $\left(1 \% \mathrm{O}_{2}\right)$ were treated with $\mathrm{H}-1$ virus, HIF-1 $\alpha$ levels were again markedly reduced at $12 \mathrm{~h}$ post-infection (Fig. 1B). Thus, H-1 viral infection significantly reduces the abundance of HIF-1 $\alpha$ protein, which is otherwise increased by hypoxia. To test whether the $\mathrm{H}-1$ virus-induced decrease in HIF-1 $\alpha$ abundance occurred at the transcriptional level, we analyzed HIF-1 $\alpha$ mRNA levels in cells infected with $\mathrm{H}-1$ virus during hypoxia. We detected no significant alteration in the abundance of HIF- $1 \alpha$ transcript after $\mathrm{H}-1$ virus treatment under hypoxia (Fig. 1C), even though HIF-1 $\alpha$ protein levels changed dramatically (Fig. 1A and B). These results suggest that $\mathrm{H}-1$ virus induces a rapid decrease in $\mathrm{HIF}-1 \alpha$ protein abundance at the post-transcriptional level.

The $H-1$ virus-induced decrease in HIF-l $\alpha$ is independent of VHL but requires proteasomes. HIF-1 $\alpha$ is degraded via its binding to VHL protein, which functions as a recognition component of the E3 ubiquitin ligase complex under normoxia $(5,6)$. Therefore, we asked whether VHL protein was involved in the H-1 virus-induced decrease in HIF- $1 \alpha$ abundance. To answer this question, we suppressed VHL protein levels using siRNA, which resulted in stable expression of HIF-1 $\alpha$ in MIA PaCa-2 cells even under normoxic conditions. When the VHL-suppressed MIA PaCa-2 cells were treated with $\mathrm{H}-1$ virus, HIF-1 $\alpha$ protein levels decreased at $12 \mathrm{~h}$ post-infection (Fig. 2A). In addition, we used a vector encoding ubiquitin carrier protein (UCP), an E2-EPF ubiquitin-conjugating enzyme, which promotes the ubiquitination and degradation of VHL (25). Introduction of UCP stabilized the expression of HIF-1 $\alpha$ in MIA PaCa-2 cells even under normoxic conditions. When the MIA PaCa-2 cells with enforced expression of UCP were treated with $\mathrm{H}-1$ virus, HIF-1 $\alpha$ protein levels decreased 
A

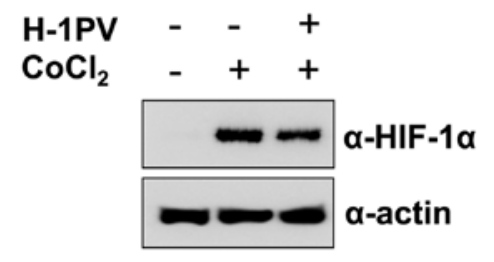

C
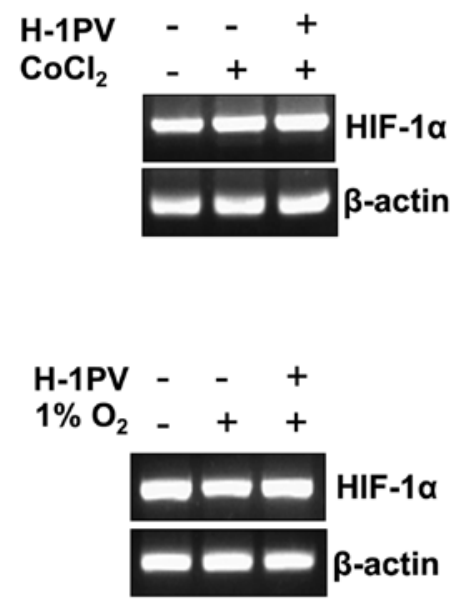

B
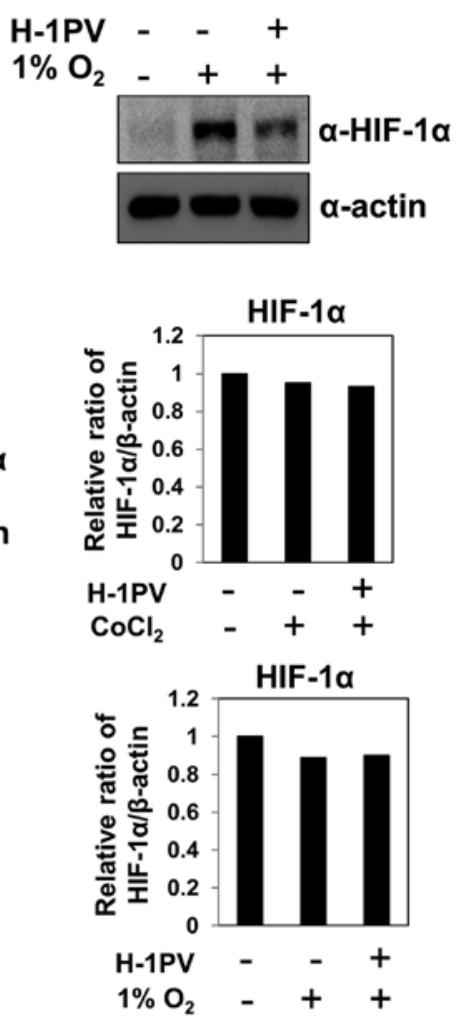

Figure 1. H-1 parvovirus infection diminishes HIF- $1 \alpha$ at the post-transcriptional level during hypoxia. (A) MIA PaCa- 2 cells were treated with CoCl ${ }_{2}(100 \mu \mathrm{M})$ to induce HIF-1 $\alpha$ and then exposed to H-1 virus $(\mathrm{MOI}=10)$. The cells were harvested at $12 \mathrm{~h}$ post-infection and the expression of HIF-1 $\alpha$ was examined by immunoblotting with an anti-HIF-1 $\alpha$ antibody. (B) MIA PaCa-2 cells were maintained and infected with $\mathrm{H}-1$ virus (MOI $=10)$ under hypoxic conditions $\left(1 \% \mathrm{O}_{2}\right)$. The cells were harvested after $12 \mathrm{~h}$ under hypoxia and the expression of HIF-1 $\alpha$ was examined by immunoblotting with an anti-HIF-1 $\alpha$ antibody. (C) MIA PaCa-2 cells were treated with $\mathrm{CoCl}_{2}$ or cultured under hypoxia and then exposed to $\mathrm{H}-1$ virus $(\mathrm{MOI}=10)$. The cells were harvested at $12 \mathrm{~h}$ postinfection. Total RNA was isolated and reverse transcribed. The HIF-1 $\alpha$ sequence was amplified using specific primers and the amplification products were visualized on $1.5 \%$ agarose gels stained with ethidium bromide. $\beta$-actin was used as an internal control. The band intensities were measured using MultiGauge version 2.1 (Fuji) and HIF-1 $\alpha$ mRNA levels were expressed relative to $\beta$-actin mRNA levels.

at $12 \mathrm{~h}$ post-infection (Fig. 2B). These results suggest that $\mathrm{H}-1$ virus-induced HIF-1 $\alpha$ degradation can proceed independent of VHL E3 ubiquitin ligase activity. Next, we investigated whether H-1 infection induced HIF-1 $\alpha$ protein degradation at the post-translational level without the involvement of VHL. MIA PaCa-2 cells with VHL knockdown or ectopic expression of UCP were treated with $\mathrm{H}-1$ virus alone or $\mathrm{H}-1$ virus plus MG132, a proteasome inhibitor. MG132 blocked H-1 virusinduced HIF-1 $\alpha$ degradation, such that the degree of HIF-1 $\alpha$ recovery was greater than in MIA PaCa-2 cells with VHL knockdown or ectopic expression of UCP alone (Fig. 2C). These results suggest that HIF-1 $\alpha$ degradation induced by H-1 infection occurs via proteasomes regardless of VHL protein levels. We wondered whether H-1 virus-induced HIF-1 $\alpha$ degradation required a new protein synthesis in the infected cells. To test this, MIA PaCa-2 cells with VHL knockdown or ectopic expression of UCP were infected with $\mathrm{H}-1$ virus in the presence of cycloheximide. As shown in Fig. 2D, the inhibition of protein synthesis with cycloheximide further enhanced the degradation of HIF-1 $\alpha$ induced by H-1 virus in MIA PaCa-2 cells under these conditions. This result implies that HIF-1 $\alpha$ degradation induced by $\mathrm{H}-1$ virus does not require a new protein synthesis, although the mechanism underlying the cycloheximide-induced acceleration of $\mathrm{H}-1$ virus-induced HIF-1 $\alpha$ degradation remains unclear.
The $H-1$ virus-induced degradation in HIF-1 $\alpha$ is independent of RACKI and HAF. Because the receptor of activated protein kinase C (RACK) 1 interacts with the PAS-A domain of HIF-1 $\alpha$ and promotes HIF- $1 \alpha$ degradation by recruiting Elongin-C/B ubiquitin ligase (26) in an $\mathrm{O}_{2} / \mathrm{PHD} / \mathrm{VHL}$-independent manner, we next asked whether RACK1 was involved in the H-1 virusinduced degradation of HIF-1 $\alpha$. We suppressed RACK1 levels with siRNA, which resulted in stable expression of HIF-1 $\alpha$ even under normoxic conditions. When RACK1-suppressed MIA PaCa- 2 cells were treated with $\mathrm{H}-1$ virus, $\mathrm{HIF}-1 \alpha$ protein levels decreased at $12 \mathrm{~h}$ post-infection (Fig. 3A). This result indicates that $\mathrm{H}-1$ virus-induced HIF-1 $\alpha$ degradation is independent of RACK1. Furthermore, we treated MIA PaCa-2 cells with 17-AAG, an HSP90 inhibitor, under $\mathrm{CoCl}_{2}$ or hypoxia because RACK1 competes with HSP90 for binding to the PAS-A domain of HIF-1 $\alpha$ (26). Treatment with 17-AAG enhanced the degradation of HIF-1 $\alpha$ protein (Fig. 3B), as seen in a previous study (26). In addition, because hypoxiaassociated factor (HAF) promotes HIF-1 $\alpha$ degradation in an $\mathrm{O}_{2}$ /VHL-independent manner (27), we wondered whether HAF played a role in the H-1 virus-induced degradation of HIF-1 $\alpha$. We repressed HAF levels with siRNA, but did not observe a significant increase in HIF-1 $\alpha$ protein levels under normoxic conditions, in contrast to the effects of VHL or RACK1 knockdown (Fig. 3C). Nonetheless, H-1 viral infec- 


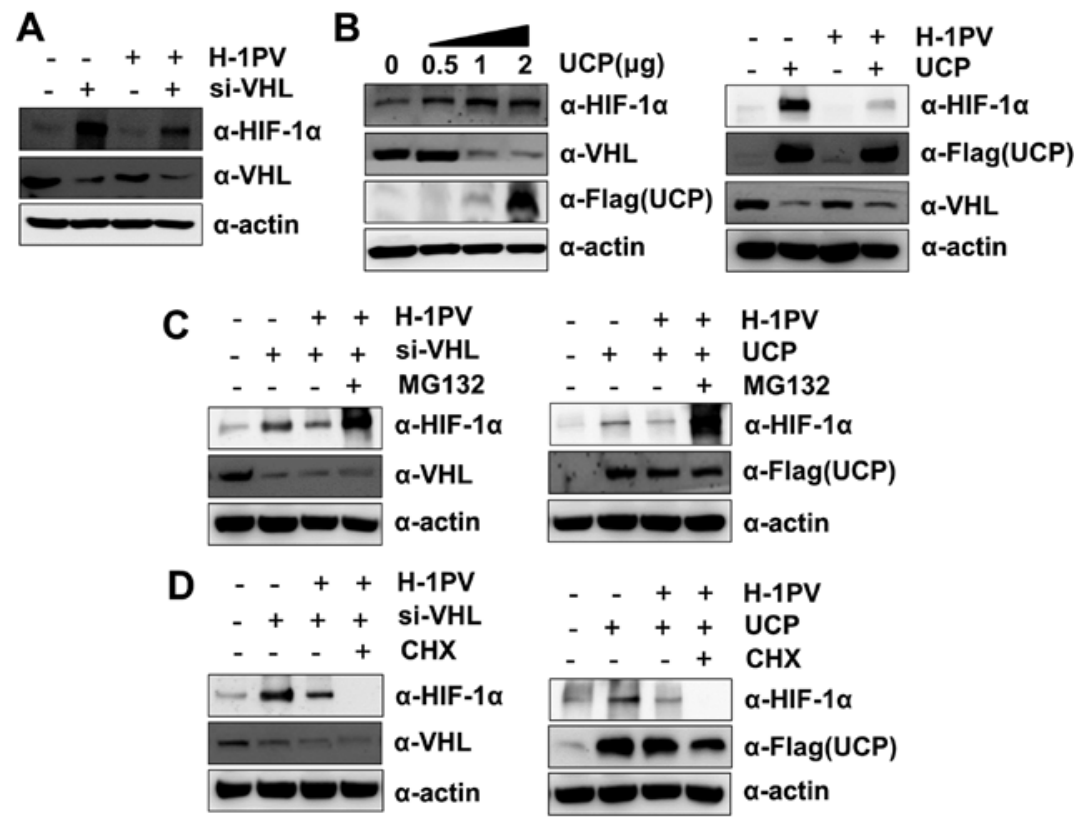

Figure 2. H-1 virus-mediated HIF-1 $\alpha$ degradation is independent of VHL but requires proteasomes. (A) MIA PaCa-2 cells were transfected with VHL siRNA $(200 \mu \mathrm{M})$ and then infected with $\mathrm{H}-1$ virus $(\mathrm{MOI}=10)$ at $24 \mathrm{~h}$ post-treatment. The cells were harvested at $12 \mathrm{~h}$ post-infection and the expression of HIF-1 $\alpha$ and VHL was examined by immunoblotting with anti-HIF-1 $\alpha$ and anti-VHL antibodies, respectively. (B) MIA PaCa-2 cells were transfected with different concentrations of a Flag-tagged UCP expression vector $(0.5,1$ and $2 \mu \mathrm{g})$. The cells were harvested at $48 \mathrm{~h}$ post-treatment and the expression of HIF-1 $\alpha$, VHL and UCP was examined by immunoblotting with the corresponding antibodies. MIA PaCa-2 cells were transfected with different concentrations of a Flag-tagged UCP expression vector and then infected with $\mathrm{H}-1$ virus $(\mathrm{MOI}=10) 24 \mathrm{~h}$ post-treatment. The cells were harvested at $12 \mathrm{~h}$ post-infection and the expression of HIF-1 $\alpha$, VHL and UCP was examined by immunoblotting with the corresponding antibodies. (C and D) MIA PaCa-2 cells were transfected with VHL siRNA or the UCP vector and then infected with $\mathrm{H}-1$ virus $(\mathrm{MOI}=10)$ at $24 \mathrm{~h}$ post-treatment. The cells were then treated with MG132 $(10 \mu \mathrm{M})$ or cycloheximide (CHX; $10 \mu \mathrm{M})$ for $8 \mathrm{~h}$ before the cells were harvested. At $12 \mathrm{~h}$ post-infection, the cell lysates were separated on 10\% SDS-PAGE gels and the expression of HIF-1 $\alpha$ VHL and UCP was examined by immunoblotting with the corresponding antibodies.

A

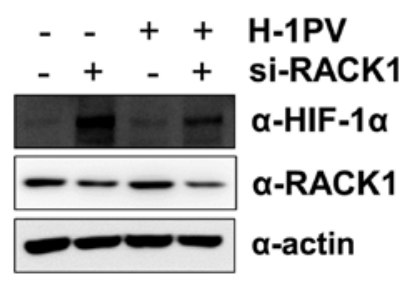

B

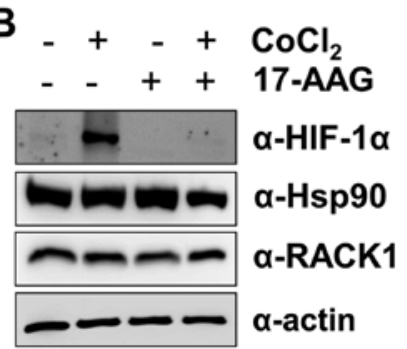

C
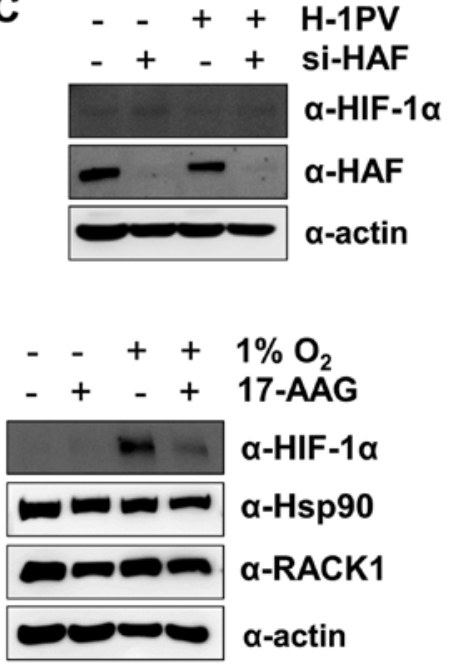

Figure 3. H-1 virus-mediated HIF-1 $\alpha$ degradation is independent of RACK1 and HAF. (A and C) MIA PaCa-2 cells were transfected with RACK1 or HAF siRNA $(200 \mu \mathrm{M})$ and then infected with $\mathrm{H}-1$ virus $(\mathrm{MOI}=10)$ at $24 \mathrm{~h}$ post-treatment. The cells were harvested at $12 \mathrm{~h}$ post-infection and the expression of HIF-1 $\alpha$ RACK1 and HAF was examined by immunoblotting with the corresponding antibodies. (B) MIA PaCa- 2 cells were treated with CoCl $\mathrm{C}_{2}$ or cultured under hypoxia and then treated with 17-AAG $(0.5 \mu \mathrm{M})$ for $12 \mathrm{~h}$. The cells were harvested and the expression of HIF-1 $\alpha$ Hsp 90 and RACK1 was examined by immunoblotting with the corresponding antibodies.

tion reduced HIF-1 $\alpha$ protein levels in HAF-suppressed MIA $\mathrm{PaCa}-2$ cells (Fig. 3C). This result also implies that H-1 virusinduced HIF-1 $\alpha$ degradation is independent of HAF.

Constitutive expression of HIF-1a limits $H$-1 virus-induced apoptosis. To investigate the biological consequence of the constitutive expression of HIF-1 $\alpha$ in cells infected with H-1 virus, we first established MIA PaCa-2 cells in which VHL was stably suppressed (Miapaca-shVHL cells) and prepared corresponding control (Miapaca-shGFP) cells. We then evaluated $\mathrm{H}-1$ virus-mediated cytotoxicity in Miapaca-shVHL cells and Miapaca-shGFP cells. Interestingly, Miapaca-shGFP 
A

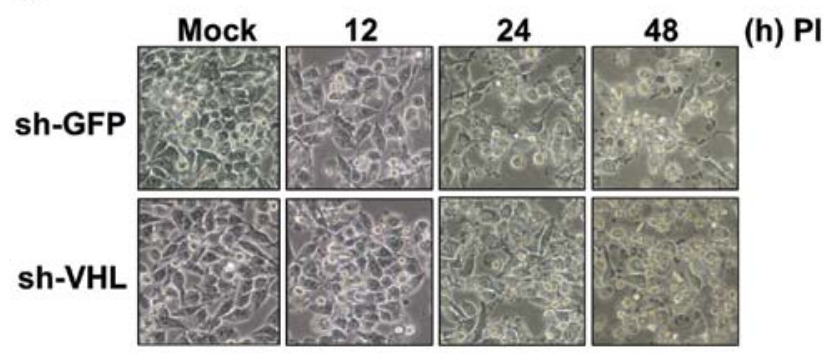

C

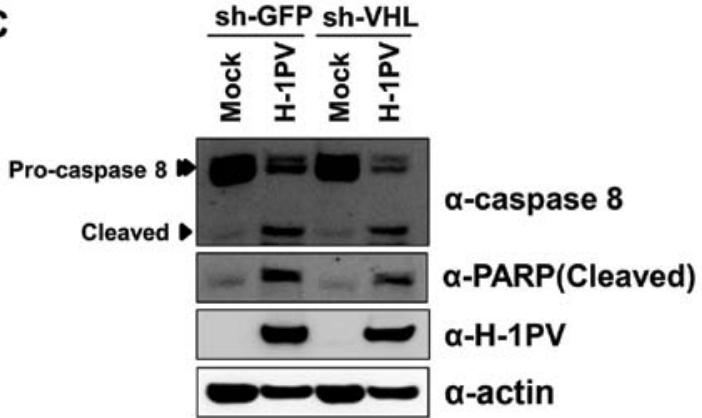

B

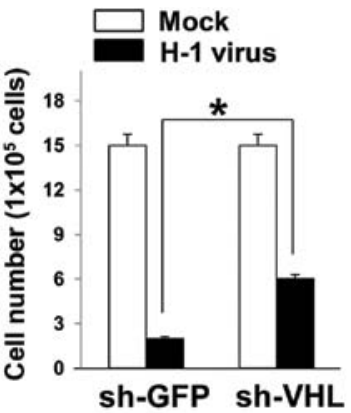

Figure 4. Constitutive expression of HIF-1 $\alpha$ limits H-1 viral replication. (A) Miapaca-shVHL and Miapaca-shGFP cells were infected with H-1 virus (MOI $=10$ ) for $48 \mathrm{~h}$ and cell viability was assessed under a light microscope. (B) Miapaca-shVHL and Miapaca-shGFP cells were infected with $\mathrm{H}-1$ virus for $48 \mathrm{~h}$ and the number of viable cells was counted using the trypan blue exclusion assay. A white bar indicates the initial cell number and a black bar indicates the cell number at $48 \mathrm{~h}$ post-infection. ${ }^{*} \mathrm{P}<0.05$ for Miapaca-shVHL cells vs Miapaca-shGFP cells. (C) Miapaca-shVHL and Miapaca-shGFP cells were infected with H-1 virus $(\mathrm{MOI}=10)$ for $48 \mathrm{~h}$ and harvested for immunoblot detection of $\mathrm{H}-1$ replication with a rabbit polyclonal anti-H-1 antibody and apoptosis with anti-caspase-8 and anti-PARP antibodies.

A

C

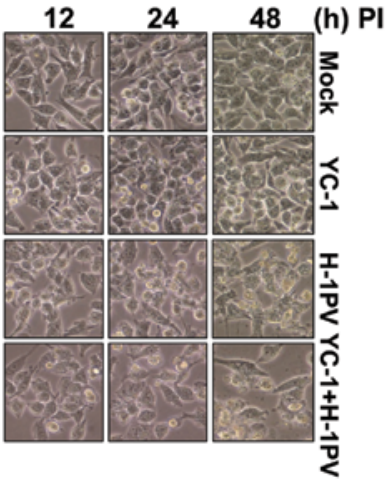

B
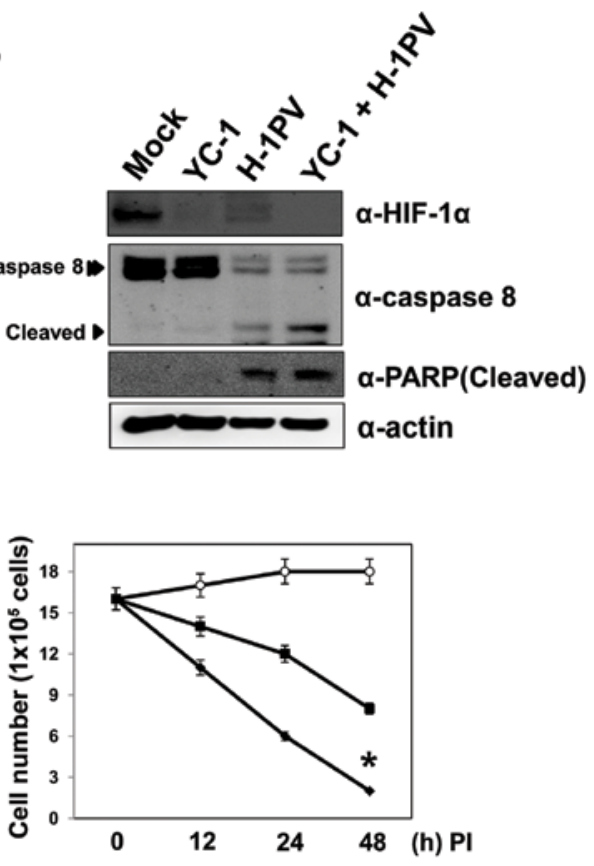

Figure 5. Combined treatment with H-1 virus and YC-1 efficiently induces apoptotic cell death in MIA PaCa-2 cells constitutively expressing HIF-1 $\alpha$. (A) MiapacashVHL cells were treated with YC-1 at 1,5, 10,30 and $50 \mu \mathrm{M}$ for $12 \mathrm{~h}$ and harvested for immunoblotting with an anti-HIF-1 $\alpha$ antibody. (B and C) Miapaca-shVHL cells were treated with YC-1 $(30 \mu \mathrm{M}), \mathrm{H}-1(\mathrm{MOI}=10)$, or YC-1 $(30 \mu \mathrm{M})$ and $\mathrm{H}-1$ virus $(\mathrm{MOI}=10)$ for $48 \mathrm{~h}$. The cells were observed under a light microscope at 12,24 and $48 \mathrm{~h}$ post-treatment to assess cell viability and the viable cell number was determined using the trypan blue exclusion assay. Open circle, YC-1; closed rectangle, $\mathrm{H}-1$; closed diamond, $\mathrm{H}-1$ virus plus $\mathrm{YC}-1$; ${ }^{*} \mathrm{P}<0.05$ for co-treatment with $\mathrm{YC}-1$ and $\mathrm{H}-1$ virus vs treatment with $\mathrm{H}-1$ virus alone The cell lysates were separated on $10 \%$ SDS-PAGE gels and the expression of HIF-1 $\alpha$, caspase 8 and PARP was examined by immunoblotting with the corresponding antibodies.

cells were more sensitive than Miapaca-shVHL cells to H-1 virus-induced cell death (Fig. 4A). When live cells lines were counted at $48 \mathrm{~h}$ post-infection using the trypan blue exclusion assay, the number of live Miapaca-shVHL cells was $\sim 2$-fold 
higher than the number of live Miapaca-shGFP cells (Fig. 4B). Next, we investigated what caused the greater sensitivity of Miapaca-shGFP cells to cell death during H-1 virus infection. We examined $\mathrm{H}-1$ capsid protein levels in whole cell lysates from $\mathrm{H}-1$ virus-infected Miapaca-shVHL and Miapaca-shGFP cells. We found that the levels of $\mathrm{H}-1$ capsid protein VP2 were higher in Miapaca-shGFP cells than in Miapaca-shVHL cells (Fig. 4C). The result suggests that greater viral replication is associated with the sensitization of Miapaca-shGFP cells to cell death. Consistent with this result, Miapaca-shGFP cells exhibited higher levels of cleaved PARP and active caspase-8 than did Miapaca-shVHL cells (Fig. 4C). Taken together, our results suggest that the constitutive expression of HIF-1 $\alpha$ in Miapaca-shVHL cells limits replication of the $\mathrm{H}-1$ virus and inhibits cellular apoptosis to some extent, although we cannot presently rule out the possibility that the suppression of VHL protein also modulates apoptotic responses through other pathways.

YC-1, a drug targeting HIF-1 $\alpha$ promotes $H$-1 virus-induced apoptosis. Because the constitutive expression of HIF-1 $\alpha$ appears to restrict $\mathrm{H}-1$ viral replication and subsequent cell death (Fig. 4), we attempted to overcome this hurdle using YC-1, a compound that targets HIF-1 $\alpha$. First, we identified the minimal concentration of YC-1 necessary to degrade HIF-1 $\alpha$ in Miapaca-shVHL cells in order to avoid the cytotoxic effects of YC-1. Although YC-1 at $50 \mu \mathrm{M}$ efficiently reduced HIF-1 $\alpha$ levels (Fig. 5A), the concentration induced apoptosis in $\sim 70 \%$ of the cells at $12 \mathrm{~h}$ post-treatment (data not shown). We therefore used YC-1 at $30 \mu \mathrm{M}$ during treatment with $\mathrm{H}-1$ virus and confirmed that degradation of HIF-1 $\alpha$ was greater after co-administration $\mathrm{YC}-1$ and $\mathrm{H}-1$ virus than after treatment with $\mathrm{H}-1$ virus or YC-1 alone. We then examined the efficiency of the co-administration killing pancreatic carcinoma Miapaca-shVHL cells. As shown in Fig. 5B, YC-1 treatment alone did not induce cell death during the treatment period. Pancreatic carcinoma Miapaca-shVHL cells showed $~ 30 \%$ cell death at $24 \mathrm{~h}$ after $\mathrm{H}-1$ viral infection alone and $50 \%$ cell death at $48 \mathrm{~h}$ post-infection (Fig. 5B). On the other hand, combined treatment with $\mathrm{YC}-1$ and $\mathrm{H}-1$ virus induced more rapid cell death: $\sim 60 \%$ at $24 \mathrm{~h}$ and $85 \%$ at $48 \mathrm{~h}$ post-treatment (Fig. 5B). We confirmed that Miapaca-shVHL cell death induced by $\mathrm{H}-1$ virus alone or by combined treatment occurred through apoptosis, with activation of caspase 8 leading to PARP cleavage (Fig. 5C). Thus, because of its ability to overcome the inhibitory effects of HIF-1 $\alpha$, co-administration of YC-1 and $\mathrm{H}-1$ virus might be an efficient strategy for the treatment of solid tumors.

\section{Discussion}

HIF-1 $\alpha$ is activated not only by hypoxia but also by a number of stimulants, including cytokines, LPS and certain bacterial infections (28). In addition, HIF-1 $\alpha$ is upregulated upon infection with hepatitis $B$ virus through its interaction with hepatitis B virus X protein (29). LMP-1, a primary oncoprotein of Epstein-Barr virus, has been reported to induce HIF-1 $\alpha$ synthesis (30). Recent studies have shown that infection with respiratory syncytial virus (RSV) stabilizes HIF-1 $\alpha$ protein via the release of nitric oxide (31) and that stabilization of
HIF-1 $\alpha$ by RSV infection does not require hypoxia (32). In contrast to studies showing that some viruses can activate HIF- $1 \alpha$, we show here that HIF-1 $\alpha$, which is often elevated in malignant tumors under hypoxic or stress conditions, is degraded following oncotropic $\mathrm{H}-1$ viral infection, with downregulation achieved at the post-transcriptional level, as seen in reoviral infection (24). We found that the downregulation of HIF-1 $\alpha$ induced by $\mathrm{H}-1$ viral infection was independent of oxygen levels and VHL. Because recent studies have reported that both RACK1 and HAF are able to trigger HIF-1 $\alpha$ degradation in a manner that is independent of oxygen, PHD and VHL $(26,27)$, we suppressed the expression of these proteins with siRNA. We found that $\mathrm{H}-1$ viral infection still reduced HIF-1 $\alpha$ protein levels under these conditions. However, the mechanism underlying $\mathrm{H}-1$ virus-mediated HIF-1 $\alpha$ degradation is still under investigation.

Many lines of evidence have shown that the constitutive expression of HIF-1 $\alpha$ functions as a hurdle to the treatment of chemotherapy- or radiotherapy-resistant cancer cells. Reovirus infection induces the degradation of HIF-1 $\alpha$ but the constitutive expression of HIF-1 $\alpha$ restricts reovirus replication to some extent (24). Other studies have shown that the renal carcinoma 786-O cell line with constitutive expression of HIF-1 $\alpha$ inhibits the replication of vesicular stomatitis virus through the upregulation of proteins involved in the immune/ defense response, such as IFN- $\beta$, OAS and interferon-stimulated genes (ISGs) (33). Therefore, we examined IFN- $\beta$ and OAS transcripts in our study. Surprisingly, we found no significant difference in the levels of IFN- $\beta$ or OAS transcripts in Miapaca-shVHL and Miapaca-shGFP cells (data not shown). This might be attributable to the different backgrounds of the cell lines and viruses.

Strategies to target HIF-1 $\alpha$, such as screening small molecules from chemical libraries, have been developed in an effort to improve the treatment of solid tumors. Several small molecule inhibitors of HIF-1 $\alpha$ activity have been shown to have antitumor and anti-angiogenic activity in addition to other known roles. These include the microtubule depolarizing agent 2-methoxyestiradiol (34); inhibitors of the redox protein thioredoxin-1 (35); YC-1, an agent developed for circulatory disorders (36); and the HSP90 inhibitor geldanamycin (37). Herein, we have described the potential utility of YC-1. Some lines of evidence indicate that the introduction of Mdm2, a HIF-1 $\alpha$ binding partner, reverses YC-1-mediated HIF-1 $\alpha$ decrease, suggesting Mdm 2 has an effect opposite that of YC-1 in the regulation of HIF-1 $\alpha$ (38). Recent studies have also shown that the $\mathrm{Akt} / \mathrm{NF}-\kappa \mathrm{B}$ signaling pathway contributes to YC-1-mediated HIF-1 $\alpha$ downregulation (39). Although we have yet to describe the detailed mechanism of the synergic effect of combined $\mathrm{YC}-1$ and $\mathrm{H}-1$ virus treatment in MIA $\mathrm{PaCa}-2$ pancreatic cancer cells constitutively expressing HIF-1 $\alpha$, we suggest that combined treatment with these two agents offers a novel strategy for the treatment of solid tumors constitutively expressing HIF-1 $\alpha$.

\section{Acknowledgements}

This study was supported by a National Research Foundation (NRF) grant funded by the Korean government (NRF-2012 R1A1A2038385). 


\section{References}

1. Hockel M and Vaupel P: Tumor hypoxia: definitions and current clinical, biologic, and molecular aspects. J Natl Cancer Inst 93: 266-276, 2001

2. Brown JM and Wilson WR: Exploiting tumour hypoxia in cancer treatment. Nat Rev 4: 437-447, 2004.

3. Bardos JI and Ashcroft M: Hypoxia-inducible factor-1 and oncogenic signalling. Bioessays 26: 262-269, 2004.

4. Jaakkola P, Mole DR, Tian YM, et al: Targeting of HIF-alpha to the von Hippel-Lindau ubiquitylation complex by $\mathrm{O}_{2}$-regulated prolyl hydroxylation. Science 292: 468-472, 2001.

5. Maxwell PH, Wiesener MS, Chang GW, et al: The tumour suppressor protein VHL targets hypoxia-inducible factors for oxygen-dependent proteolysis. Nature 399: 271-275, 1999.

6. Tanimoto K, Makino Y, Pereira T and Poellinger L: Mechanism of regulation of the hypoxia-inducible factor-1 alpha by the von Hippel-Lindau tumor suppressor protein. EMBO J 19: 4298-4309, 2000.

7. Bardeesy $\mathrm{N}$ and DePinho RA: Pancreatic cancer biology and genetics. Nat Rev Cancer 2: 897-909, 2002.

8. Maitra A and Hruban RH: Pancreatic cancer. Annu Rev Pathol 3: $157-188,2008$.

9. Hawes RH, Xiong Q, Waxman I, Chang KJ, Evans DB and Abbruzzese JL: A multispecialty approach to the diagnosis and management of pancreatic cancer. Am J Gastroenterol 95: 17-31, 2000 .

10. Safran H, Iannitti D, Ramanathan R, et al: Herceptin and gemcitabine for metastatic pancreatic cancers that overexpress HER-2/neu. Cancer Invest 22: 706-712, 2004.

11. Xiong HQ, Rosenberg A, LoBuglio A, et al: Cetuximab, a monoclonal antibody targeting the epidermal growth factor receptor, in combination with gemcitabine for advanced pancreatic cancer: a multicenter phase II trial. J Clin Oncol 22: 2610-2616, 2004.

12. Van Cutsem E, van de Velde H, Karasek P, et al: Phase III trial of gemcitabine plus tipifarnib compared with gemcitabine plus placebo in advanced pancreatic cancer. J Clin Oncol 22: 1430-1438, 2004

13. Kasuya H, Takeda S, Nomoto S and Nakao A: The potential of oncolytic virus therapy for pancreatic cancer. Cancer Gene Ther 12: 725-736, 2005 .

14. Kuhlmann KF, Gouma DJ and Wesseling JG: Adenoviral gene therapy for pancreatic cancer: where do we stand? Dig Surg 25 : 278-292, 2008

15. Cornelis JJ, Lang SI, Stroh-Dege AY, Balboni G, Dinsart C and Rommelaere J: Cancer gene therapy through autonomous parvovirus-mediated gene transfer. Curr Gene Ther 4: 249-261, 2004.

16. Paradiso PR, Williams KR and Costantino RL: Mapping of the amino terminus of the $\mathrm{H}-1$ parvovirus major capsid protein. J Virol 52: 77-81, 1984.

17. Chen AY and Qiu J: Parvovirus infection-induced cell death and cell cycle arrest. Future Virol 5: 731-743, 2010.

18. Di Piazza M, Mader C, Geletneky K, et al: Cytosolic activation of cathepsins mediates parvovirus $\mathrm{H}$-1-induced killing of cisplatin and TRAIL-resistant glioma cells. J Virol 81: 4186-4198, 2007.

19. Kiprianova I, Thomas N, Ayache A, et al: Regression of glioma in rat models by intranasal application of parvovirus h-1. Clin Cancer Res 17: 5333-5342, 2011.

20. Geletneky K, Huesing J, Rommelaere J, et al: Phase I/IIa study of intratumoral/intracerebral or intravenous/intracerebral administration of Parvovirus H-1 (ParvOryx) in patients with progressive primary or recurrent glioblastoma multiforme: ParvOryx01 protocol. BMC Cancer 12: 99, 2012.

21. Grekova SP, Aprahamian M, Daeffler L, et al: Interferon gamma improves the vaccination potential of oncolytic parvovirus $\mathrm{H}-1 \mathrm{PV}$ for the treatment of peritoneal carcinomatosis in pancreatic cancer. Cancer Biol Ther 12: 888-895, 2011.
22. Dempe S, Stroh-Dege AY, Schwarz E, Rommelaere J and Dinsart C: SMAD4: a predictive marker of PDAC cell permissiveness for oncolytic infection with parvovirus H-1PV. Int J Cancer 126: 2914-2927, 2010.

23. Halder S, Nam HJ, Govindasamy L, et al: Production, purification, crystallization and structure determination of $\mathrm{H}-1$ Parvovirus. Acta Crystallogr Sect F Struct Biol Cryst Commun 68: 1571-1576, 2012

24. Cho IR, Koh SS, Min HJ, et al: Down-regulation of HIF-1alpha by oncolytic reovirus infection independently of VHL and p53. Cancer Gene Ther 17: 365-372, 2010.

25. Jung CR, Hwang KS, Yoo J, et al: E2-EPF UCP targets pVHL for degradation and associates with tumor growth and metastasis. Nat Med 12: 809-816, 2006.

26. Liu YV, Baek JH, Zhang H, Diez R, Cole RN and Semenza GL: RACK1 competes with HSP90 for binding to HIF-1alpha and is required for $\mathrm{O}(2)$-independent and HSP90 inhibitor-induced degradation of HIF-1alpha. Mol Cell 25: 207-217, 2007.

27. Koh MY, Darnay BG and Powis G: Hypoxia-associated factor, a novel E3-ubiquitin ligase, binds and ubiquitinates hypoxiainducible factor 1alpha, leading to its oxygen-independent degradation. Mol Cell Biol 28: 7081-7095, 2008.

28. Kim HY, Kim YH, Nam BH, et al: HIF-1alpha expression in response to lipopolysaccaride mediates induction of hepatic inflammatory cytokine TNFalpha. Exp Cell Res 313: 1866-1876, 2007.

29. Yoo YG, Oh SH, Park ES, et al: Hepatitis B virus X protein enhances transcriptional activity of hypoxia-inducible factor1alpha through activation of mitogen-activated protein kinase pathway. J Biol Chem 278: 39076-39084, 2003.

30. Wakisaka N, Kondo S, Yoshizaki T, Murono S, Furukawa M and Pagano JS: Epstein-Barr virus latent membrane protein 1 induces synthesis of hypoxia-inducible factor 1 alpha. Mol Cell Biol 24: 5223-5234, 2004.

31. Kilani MM, Mohammed KA, Nasreen N, Tepper RS and Antony VB: RSV causes HIF-1alpha stabilization via NO release in primary bronchial epithelial cells. Inflammation 28: 245-251, 2004.

32. Haeberle HA, Durrstein C, Rosenberger P, et al: Oxygenindependent stabilization of hypoxia inducible factor (HIF)-1 during RSV infection. PLoS One 3: e3352, 2008.

33. Hwang II, Watson IR, Der SD and Ohh M: Loss of VHL confers hypoxia-inducible factor (HIF)-dependent resistance to vesicular stomatitis virus: role of HIF in antiviral response. J Virol 80: 10712-10723, 2006.

34. Escuin D, Kline ER and Giannakakou P: Both microtubulestabilizing and microtubule-destabilizing drugs inhibit hypoxiainducible factor-1alpha accumulation and activity by disrupting microtubule function. Cancer Res 65: 9021-9028, 2005.

35. Welsh SJ, Williams RR, Birmingham A, Newman DJ, Kirkpatrick DL and Powis G: The thioredoxin redox inhibitors 1-methylpropyl 2-imidazolyl disulfide and pleurotin inhibit hypoxia-induced factor lalpha and vascular endothelial growth factor formation. Mol Cancer Ther 2: 235-243, 2003.

36. Yeo EJ, Chun YS, Cho YS, et al: YC-1: a potential anticancer drug targeting hypoxia-inducible factor 1 . J Natl Cancer Inst 95: $516-525,2003$.

37. Mabjeesh NJ, Post DE, Willard MT, et al: Geldanamycin induces degradation of hypoxia-inducible factor lalpha protein via the proteosome pathway in prostate cancer cells. Cancer Res 62: 2478-2482, 2002

38. Lau CK, Yang ZF, Lam CT, Tam KH, Poon RT and Fan ST: Suppression of hypoxia inducible factor-1alpha (HIF-1alpha) by YC-1 is dependent on murine double minute 2 (Mdm2). Biochem Biophys Res Commun 348: 1443-1448, 2006.

39. Sun HL, Liu YN, Huang YT, et al: YC-1 inhibits HIF-1 expression in prostate cancer cells: contribution of Akt/NF-kappaB signaling to HIF-1alpha accumulation during hypoxia. Oncogene 26: 3941-3951, 2007. 